\title{
UMA REFLEXÃO SOBRE O FATOR MOTIVACIONAL NO DESENVOLVIMENTO DA ORALIDADE EM LÍNGUA INGLESA PARA O PROFESSOR EM FORMAÇÃO
}

\author{
A reflection about the motivational factor in the development of oral ability in English for \\ pre-service teachers
}

Giselle Ludka DEITOS, UFPR- PG ${ }^{1}$

RESUMO: Esse trabalho tem como objetivo principal discutir o fator motivacional no desenvolvimento da oralidade em língua inglesa dentro do ambiente acadêmico, levando em consideração os estudantes de Letras (Português-Inglês). Presume-se que o fator motivacional dentro da oralidade em uma língua estrangeira perpassa as crenças desse professor em torno do idioma, bem como as experiências que esse vivenciou antes de se tornar um profissional de Letras.

PALAVRAS-CHAVE: Motivação; professor em formação; língua inglesa.

ABSTRACT: This work aims at discussing the motivational factor in the development of the oral ability in the English language inside the scholastic environment with the students of Letras (Portuguese-English). It is assumed that the motivational factor regarding the oral ability of a foreign language passes through the beliefs of this teacher about the language, as well as the experiences that this one lived before becoming a professional in Letras.

KEYWORDS: Motivation; pre-service teacher; English language

\section{INTRODUÇÃO}

Com o objetivo de compreender o fator motivacional na formação continuada do professor de língua inglesa, surgiu o interesse em investigar o desenvolvimento da oralidade nessa língua estrangeira. Pretende-se averiguar o que leva o professor em formação que já atua em sala-de-aula a dar continuidade à sua formação na língua inglesa, no que diz respeito à oralidade, e quais são os fatores motivacionais que estão incorporados nesse processo. Neste trabalho, no entanto, apresentaremos apontamentos iniciais a respeito da motivação e da oralidade com base em pressupostos teóricos, uma vez que a investigação encontra-se em fase inicial.

\footnotetext{
${ }^{1}$ Mestranda em Letras, área de concentração em Estudos Linguísticos, UFPR.
} 
Denominamos nesse trabalho o profissional de Letras como professor em formação continuada e em serviço para melhor explicar essa situação onde queremos investigar dois momentos distintos; esse professor na situação de acadêmico, ou seja, de aprendiz da língua inglesa e de profissional de uma escola regular. Vê-se como fundamental nesse processo compreender quais fatores motivacionais o professor e ao mesmo tempo aprendiz tem buscado para obter o êxito desejado na apreensão da língua inglesa, no que tange à oralidade. Levandose em conta que o professor de língua inglesa pode ficar suscetível a fazer apenas o uso de sua língua materna na condução da aula da língua inglesa, limitando o uso do dessa a explicações, como, por exemplo, leitura de frases, sentiu-se a necessidade de analisar de forma mais detalhada a questão da oralidade presente (ou não) em sala de aula, estabelecendo os motivos que minimizam o seu uso por parte do docente. Presume-se que a falta ou o pouco uso do idioma estrangeiro acontece devido à falta de motivação do professor, pois o mesmo pode considerar o seu conhecimento linguístico insuficiente, inadequado ou até mesmo incorreto. Com o receio de ser induzido a um possível erro, seja ele sintático, semântico ou até de pronúncia, tal professor pode fazer um uso limitado do idioma em questão durante a sua prática.

Compreendemos a motivação, tendo como referência Dörnyei (1998), como um fatorchave que insere esse professor e ao mesmo tempo aprendiz na manutenção contínua de tudo que possa influenciar de forma positiva o manejo de seu uso oral junto à língua estrangeira mencionada. Esse fator também é compreendido como um nivelador do sucesso e o impulso para dar sequência ao processo de ensino-aprendizagem de uma língua estrangeira. A hipótese que podemos destacar aqui é que a motivação proveniente, neste caso, trata-se de algum tipo de esforço e dedicação pessoais do professor.

Este artigo está organizado em 3 partes. Na seção a seguir, daremos algumas definições para o termo motivação. Na parte 2, comenta-se à respeito da formação do professor levando-se em conta o foco na habilidade oral. Na seção 3, fala-se brevemente do papel da oralidade na língua estrangeira. 


\section{DEFININDO MOTIVAÇÃO}

Entender os aspectos motivacionais que vêm ao encontro do processo de formação acadêmica, bem como as experiências que antecederam o ingresso ao curso de Letras podem auxiliar para um melhor entendimento do tópico motivação para um profissional de Letras em dois momentos cabais de sua profissão: uma vez inserido no contexto de aluno, dentro da instituição acadêmica; e também de sua inserção no âmbito escolar, agora como professor de língua inglesa. Como nosso objetivo aqui é averiguar o processo motivacional, atendo-nos ao quesito oralidade, vamos explorar de forma mais minuciosa alguns dos aspectos que instigam o uso ou não da habilidade oral no contexto acadêmico e escolar, onde esse professor e aprendiz tem a oportunidade de comunicar-se na língua em questão. É importante também, anteriormente a definição de motivação, destacar a pergunta norteadora nessa pesquisa em andamento, direcionada a esses professores: "Que sentimentos vêm à tona quando você tem a oportunidade de comunicar-se na língua estrangeira?"

Para Nunan (1999, p.232), motivação é a junção dos esforços e da vontade de chegar ao objetivo almejado junto à língua estrangeira juntamente com as atitudes tomadas por esse aprendiz. Desta forma percebe-se que a atitude positiva proveniente do aprendiz desempenhará papel relevante no resultado do processo de aprendizagem, trazendo assim implicações com relação ao uso efetivo do idioma em todas as habilidades linguísticas. Uma predisposição a estar exposto num ambiente propício à real apreensão do idioma, bem como o esforço por parte do aprendiz em colocar o conhecimento apresentado dentro de um contexto significativo, parece determinar o progresso da aprendizagem na língua estrangeira. O aprendiz necessita estar ciente de que, para que sua comunicação em língua estrangeira surta efeito, ele deve utilizar as mesmas estratégias com que desenvolve sua comunicação em língua materna. Isso quer dizer que dentro da língua inglesa os critérios de aprendizagem devem levar em conta situações que possibilitem além de interpretação textual, leituras e escuta, situações de fala. Assim, todo e qualquer conhecimento teórico deve ser aplicado na linguagem em uso para, a partir daí, estabelecer sentidos significativos com relação ao discurso desejado.

Dörnyei (1998, p.118), alerta que existe uma noção geral da definição do termo motivação por grande parte dos pesquisadores da área, e, que tal aspecto, pode levar a um entendimento muito superficial do tema. Para ele, é necessário especificar em que âmbitos se 
está definindo motivação, uma vez que o termo pode ser abordado com diferentes sentidos (e.g. afeto, traço de personalidade, energia mental).

A motivação não é mais vista como um reflexo de certas forças internas como, por exemplo, instintos, volição, vontade e energia física; nem é vista em termos comportamentais severos como uma função de estímulos e reforço. Preferencialmente, as abordagens cognitivas atuais colocam o foco nos pensamentos e crenças individuais (e recentemente também, nas emoções) que são transformadas em ações. ${ }^{2}$ (nossa tradução)

Um novo termo vem sendo aplicado junto às teorias sobre motivação. Falamos do termo Investimento, utilizado por Norton (2008). Antes de ser mencionado por Norton, Bourdieu (1977) inicia o uso do termo usado aqui Norton defende que, diferente de motivação onde os aprendizes são categorizados da mesma forma (as diferentes personalidades são englobadas de forma unitária), a noção de investimento vem atender à demanda de diferenças calcadas nas inúmeras possibilidades de traço de personalidade, obedecendo, assim, situações diferenciadas de aprendizes, mesmo esses estando num similar contexto de aprendizagem. Isso oferece base para que se entenda a generalização que se faz com o tema motivação, que pode levar a conclusões precipitadas quando se menciona que um aprendiz tem alguma deficiência motivacional.

Gardner (1960, p.7) define motivação no âmbito da aprendizagem de uma língua estrangeira, dentro de um parâmetro onde existe algum tipo de interesse do aprendiz; interesse esse que se limita a algum tipo de avaliação que o mesmo realizará, alguma atividade relacionada à oferta de emprego, ou a algum resultado positivo esperado em determinada questão relacionada à língua estrangeira. Tal motivação para ele parece, na maioria das vezes, operar por um curto período de tempo, já que o objetivo do aprendiz tende a se limitar dentro de um fator isolado. Ele ainda acrescenta que é improvável que a motivação na língua estrangeira continue depois que o objetivo desejado é alcançado.

\footnotetext{
${ }^{2}$ Motivation is no longer seen as a reflection of certain inner forces such as instincts, volition, will and physical energy; neither is it viewed in strictly behavioural terms as a function of stimuli and reinforcement. Rather, current cognitive approaches place the focus on the individual's thoughts and beliefs (and recently also emotions) that are transformed into actions. ${ }^{2}$
} 


\section{O PROFESSOR DENTRO DE SEU PROCESSO DE FORMAÇÃO}

Acredita-se que, de alguma forma, as experiências que embasam todo o processo de aprendizagem, nesse caso específico, o professor em formação, possuem influência efetiva na forma com que esse profissional conduz o seu perfil na busca de novos conhecimentos ou aprimoramento do que já conhece. Sendo assim, as estratégias que o fazem apreender mais os novos conteúdos devem ter ligação direta com a metodologia que prescreveu o seu papel de aluno em todo o processo de formação.

Presume-se que, em algum momento antes da entrada na universidade, esse acadêmico teve contato com o inglês, seja dentro de um aspecto formalizado, ou seja, frequentando aulas do idioma estrangeiro em alguma instituição de línguas, ou mesmo, de forma menos controlada, tomando a iniciativa de buscar o conhecimento por conta própria. Para Abrahão (2002), as crenças que o professor em formação traz para o ambiente acadêmico devem ser levadas em consideração e posteriormente explicitadas para serem objetos de uma reflexão. Acredita-se que essas crenças devem ter instigado a intenção de fazer do inglês instrumento de trabalho desse professor. Nessa perspectiva, vale detectar a questão da motivação dentro de ao menos, um aspecto da língua em que tal aprendiz sentiu facilidade no desempenho. Entre essas habilidades, lembramos da leitura, da escrita, da fala ou da escuta. Para Brown (2007) o sucesso na língua inglesa requer que o aprendiz seja mais responsável pelo seu processo de aquisição, e, essa tarefa é denominada Investimento.

Brown (2007, p.258), também trata os esforços realizados pelo professor em sua formação como, um investimento estratégico, que é a definição dada para os estudos autodidáticos que permeiam a formação docente continuada. Dentro desse investimento são destacados dois itens-chaves, a saber: a dedicação de tempo e esforço. Da mesma forma que a dedicação é evidenciada em outros campos do conhecimento, a aprendizagem de uma língua demanda alguns mecanismos, dentre os quais podemos citar o monitoramento, a observação e a prática.

Barcelos (1995, p.83) menciona que dentro das crenças dos professores que falam sobre o que acreditam ajudar na aquisição de línguas estrangeiras, a atividade de ouvir músicas na língua-alvo é a que mais auxilia. Vemos nesse procedimento, uma forma de instigar o melhor desenvolvimento da oralidade que o professor pode usar a seu favor, tanto para a sua própria formação, quanto para utilização em sala de aula com seus alunos. 
Almeida Filho (2010, p.11) relata toda a experiência vivida previamente pelo professor quando esse é ou foi inserido na situação de aprendiz. Para ele,

\begin{abstract}
Essas tradições de ensinar línguas nas escolas exercem influências variáveis sobre o professor, que por sua vez traz para o ensino disposições pessoais e valores desejáveis de sua própria abordagem. O conjunto de forças das tradições de ensinar, social e institucionalmente marcadas, tem de se integrar de alguma forma com as contribuições pessoais (da abordagem) do professor.
\end{abstract}

Toda essa experiência parece futuramente influenciar na conduta do professor diante da língua estrangeira. Presumimos que, as motivações pessoais desse professor tendem a conduzir as práticas orais por ele adotadas. Vemos nessa temática também, as crenças do professor diante de sua visão de língua estrangeira. Supõe-se que, se a visão é um fenômeno positivo, onde a nova língua possa ter oportunidade efetiva de uso, por exemplo, tal profissional mostrará a priori, uma conduta que facilitará a condução da aula de língua inglesa.

\title{
O PAPEL DA ORALIDADE
}

Entendemos, nesse trabalho, que oralidade é todo o uso da língua estrangeira em questão, utilizada pelo professor no contínuo de sua aula, junto aos alunos. Essas situações de oralidade, além de ocorrer em sala-de-aula, podem expandir-se em momentos cotidianos desse profissional de línguas, e também na universidade em que se prepara na sua formação inicial como docente. Em situação escolar, tal uso seria feito a qualquer momento da aula, onde o idioma estrangeiro seria a ferramenta para que os alunos compreendessem alguma informação proveniente do professor e, talvez, dando a oportunidade dos aprendizes o fazerem também.

Quando se fala em oralidade, prontamente fazemos uma conexão com a Abordagem Comunicativa, que de início nos dá uma prévia ideia de ser a abordagem que privilegiará tal habilidade da língua. De acordo com Lightbown e Spada (2006, p.38) os modelos instaurados por Krashen $^{3}$ se apresentam na transição de métodos estruturais para aqueles que privilegiavam

\footnotetext{
${ }^{3}$ Krashen formula cinco hipóteses que influenciam o aprendiz na aquisição de uma língua estrangeira. Primeiramente, ele diferencia aprendizagem de aquisição, onde essa última trata-se de um processo inconsciente diferentemente da primeira, que é consciente. As cinco hipóteses de Krashen são: the acquisition-learning hypothesis (hipótese da aquisição/aprendizagem), the natural order hypothesis ( a hipótese da ordem natural), the monitor hypothesis (hipótese do monitor), the input hypothesis (hipótese do insumo), the affective filter hypothesis ( hipótese do filtro afetivo).
} 
os aspectos mais comunicativos. Para eles, algumas instruções que se baseiam na habilidade oral demonstram que os aprendizes alcançam melhores progressos juntamente à língua estrangeira. E essa condição presume ter influência com o "input" que o aluno recebe em determinado momento em sala de aula, fazendo com que o mesmo tenha maiores possibilidades de uso do idioma estrangeiro baseadas no que já recebeu de informação. No entanto, para Neto (2006, p.31), “os métodos e abordagens não parecem deixar claras as formas como se devem seqüenciar ou avaliar o desenvolvimento das habilidades orais dos alunos."

Almeida Filho (2010, p.25) destaca que na maioria das vezes, o ambiente escolar é a única oportunidade que o aprendiz tem de contato com os aspectos comunicativos na língua estrangeira, e onde mecanismos para construir significados no idioma estrangeiro são desenvolvidos.

Para Costa $(2009$, p. 28, 29)

[...] relativamente à oralidade é verificável que para se saber comunicar é necessário adaptar a forma linguística à intenção e à situação de comunicação. Para levar a cabo estes pressupostos as opções metodológicas - implementadas pelo professor, visto aqui como um comunicador - apontam para a valorização da oralidade mais na vertente do processo do que do produto, uma vez que se organiza as atividades comunicativas em fases de execução, iniciando-se com a apresentação da tarefa introduzindo-se a temática e/ou o vocabulário - através da língua-alvo, podendo a língua materna ser utilizada como forma de garantir a compreensão dos enunciados.

\section{CONSIDERAÇÕES FINAIS}

Com base em estudos que mencionam as crenças de professores de línguas estrangeiras, obtemos suporte para compreender o processo de construção de conhecimento pelo qual os profissionais de Letras em processo de formação continuada passam, e presumimos que muito do que esses professores acreditam, acaba refletindo na postura que adotam na condução de seu preparo profissional. Assim, a visão que esse profissional tem da importância da oralidade quando se ensina uma língua estrangeira parece determinar muito do que ele fará com tal habilidade em sala de aula. O que podemos assumir inicialmente é que, todas as atitudes tomadas por esse professor ao longo de seu desempenho profissional juntamente aos seus alunos perpassam os caminhos trilhados por esse dentro de sua vivência prévia com a mencionada língua. Se ele teve uma predisposição à oralidade em língua inglesa, certamente continuará dando créditos a essa habilidade quando em sala de aula. 
Destacamos alguma importância na diferenciação prevista em Norton, quando tiramos o foco de apenas compreender o fenômeno motivacional em âmbitos gerais e abrimos espaço para o termo investimento, onde podemos enfatizar a motivação de forma mais individualizada. Essa separação parece facilitar a compreensão do fenômeno motivacional, pois isso nos leva a concluir previamente que cada experiência singular vem trazer diferentes resultados quando o assunto é a eficiência do professor junto ao seu desenvolvimento oral na língua inglesa. Ainda sobre o aspecto motivacional, evidenciamos que o termo é bastante multifacetado, pois, do ponto de vista dos pesquisadores da área, podemos entendê-lo através de diferentes posições, de acordo com os objetivos diferenciados que variam entre as necessidades dos aprendizes de língua estrangeira. 


\section{REFERÊNCIAS}

ABRAHÃO, M. H. V. Teoria e prática na formação pré-serviço do professor de língua estrangeira. In: GIMENEZ, T. (organizadora). Trajetórias na formação de professores de línguas. Londrina: Ed. UEL, 2002, p. 59 - 73.

ALMEIDA FILHO, J. C.P. Dimensões comunicativas no ensino de línguas. Campinas-SP: Editora Pontes, 2010.

BARCELOS, A. M. F. A cultura de aprender língua estrangeira (inglês) de alunos formandos de Letras. Dissertação de mestrado. UNICAMP, Campinas, 1995.

BROWN, H. D. Teaching by principles: an interactive approach to language pedagogy. 3 rd edition. New York: Longman, 2007.

COSTA, M. I. A. A oralidade no processo de ensino-aprendizagem das línguas-culturas estrangeiras: um estudo de caso na disciplina de Inglês no contexto escolar português. Dissertação de mestrado em Educação. Universidade do Minho, Braga, 2009.

DÖRNYEI, Z. Motivation in second and foreign language learning. Thames Valley University, London, 1998.

Disponível em: http://journals.cambridge.org/abstract_S026144480001315X. Acesso em 15 out 2013. GARDNER, R. C. Motivational Variables in Second-Language Acquisition. Tese de Doutorado. McGill University, 1960.

GIMENEZ,T. Trajetórias na formação de professores de línguas.Londrina: Ed. UEL 2002. LIGHTBOWN, P. M.; SPADA A. N. How languages are learned. 3a. ed. Oxford: Oxford University Press, 2006.

NETO , T. N. Uma concepção alternativa de educação formal aplicada ao ensino de pronúncia de inglês. Tese de Doutorado. UFMG, Belo Horizonte, 2006.

NORTON, B.; GAO, Y. Identity, investment, and Chinese learners of English. University of British Columbia, Canada / Peking University, China, 2008. Disponível em: http://faculty.educ.ubc.ca/norton/Norton\%20\&\%20Gao\%202008.pdf. Acesso em 20 set 2013. NUNAN, D. Second language teaching and learning. Boston: Heinle \&Heinle, 1999. 